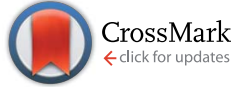

Cite this: RSC Adv., 2017, 7, 13240

Received 19th October 2016

Accepted 21st February 2017

DOI: $10.1039 / c 6 r a 25469 a$

rsc.li/rsc-advances

\section{Eosin Y-catalyzed photooxidation of triarylphosphines under visible light irradiation and aerobic conditions $\uparrow$}

\author{
Yanbin Zhang, ${ }^{b}$ Cong Ye, ${ }^{b}$ Shijie Li, ${ }^{b}$ Aishun Ding, ${ }^{b}$ Guangxin Gu*a and Hao Guo*b \\ We report herein a novel method for Eosin Y-catalyzed photooxidation of triarylphosphines under visible \\ light irradiation and aerobic conditions. This new approach employed visible light as the energy source \\ and air as the oxidant, showing great advantages in environmental benignness and operational easiness \\ with a wide functional group tolerance.
}

Photochemistry is an important branch in modern chemistry. ${ }^{1}$ Distinct from traditional thermal reactions, the key intermediates in photo-reactions are the electronically excited state of organic molecules. Photochemical sensitization of triplet oxygen to singlet oxygen is one of the appealing aspects of photochemistry. ${ }^{2}$ Compared with chemical decomposition, electro-chemical, bio-chemical and other methods, ${ }^{3}$ photochemical sensitization is cheap, easy to handle, efficient and environment-friendly. More importantly, organic photocatalysts are easy to functionalize, which means the catalyst could be attached to advanced materials ${ }^{4}$ and bio-materials. ${ }^{5}$ Several photocatalysts were used in singlet oxygen generation. ${ }^{6}$ Among them, the structure of Eosin $\mathrm{Y}$ showed good features, such as aqueous solubility and easiness to modify (Scheme 1). Thus, much attention has been paid to Eosin Y-catalyzed singlet oxygen generation.?

Phosphine oxide is an important fragment in medicine, ${ }^{8}$ and functional supramoleculars. ${ }^{9}$ It also plays an important role in organic synthesis. ${ }^{10}$ It has been used as a catalyst for the Wittig reaction, ${ }^{11}$ a ligand for transitional metals, ${ }^{12}$ and as a gentle oxidant. ${ }^{13}$ Numerous methods have been developed for the

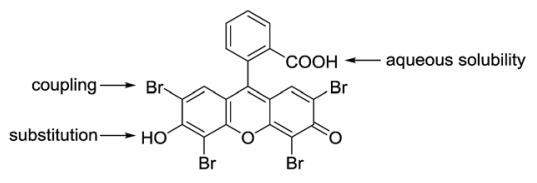

Scheme 1 Structure feature of Eosin $Y$.

${ }^{a}$ Department of Materials Science, Fudan University, 220 Handan Road, Shanghai, 200433, P. R. China. E-mail: guangxingu@fudan.edu.cn; Fax: +86-21-65648837; Tel: $+86-21-65648837$

${ }^{b}$ Department of Chemistry, Fudan University, 220 Handan Road, Shanghai, 200433, P. R. China. E-mail: Hao_Guo@fudan.edu.cn; Fax: +86-21-55664361; Tel: +86-2155664361

$\dagger$ Electronic supplementary information (ESI) available: Experimental procedures, and characterization data for all compounds. See DOI: 10.1039/c6ra25469a preparation of phosphine oxides from phosphines via direct oxidations, ${ }^{14,15}$ among which some photocatalysts, such as $9,10-$ dicyanoanthracen, ${ }^{15 b}$ 9-mesityl-10-methylacridinium perchlorate, ${ }^{15 c}$ and sensitizers generating singlet oxygen ${ }^{15 d}$ showed nice catalytic activity. ${ }^{15}$ However, in many cases, external environmentally harmful oxidants, ${ }^{14 a}$ expensive additives, ${ }^{14 b}$ or harsh conditions ${ }^{14 c}$ were required. Moreover, stoichiometric oxidants will generate stoichiometric wastes, which makes the purification process much more complicated. ${ }^{14 b}$ An efficient, environmentally friendly, and convenient method for the oxidation of phosphines is desirable as part of an overall effort to develop "Green Chemistry". With our continuous interest in this field, ${ }^{16}$ we turned to study the Eosin Ycatalyzed photo oxidation of triarylphosphines based on the following considerations. Firstly, Eosin Y is cheap and the loading of the catalyst is generally low. Secondly, harsh irradiation conditions can be avoided, since Eosin Y absorbs visible light. Thirdly, Eosin $\mathrm{Y}$ is stable in air and absorbs visible light, thus, special glassware and protective gas is no more required. This will provide operational convenience. Here in, we wish to report our recent results in the photooxidation of triarylphosphines using Eosin $\mathrm{Y}$ as the catalyst under visible light irradiation and aerobic conditions.

Our initial attempts were carried out using triphenylphosphine 1a as the model substrate, $15 \mathrm{~mol} \%$ of Eosin $\mathrm{Y}$ as the catalyst, a $23 \mathrm{~W}$ household lamp as the light source, and oxygen as the oxidant. A quantitative yield of the corresponding triphenylphosphine oxide $2 \mathbf{a}$ was obtained in all tested solvents (entries 1-6, Table 1). Given that the reaction in methanol showed the highest reaction speed (entry 6, Table 1), methanol was chosen as the standard solvent. However, when we tried to explore the substrate scope, some reactants were not dissolved in methanol. Thus, a mixture of dichloromethane (DCM) : methanol (MeOH) $=5: 1$ was used as the optimal solvent (entry 7 , Table 1 ). Further studies showed that the loading of catalyst could be dramatically reduced (entries 7-10, Table 1). We were delight to see that only 1 mol\% of Eosin Y was enough to efficiently catalyze this transformation (entry 10, Table 1). Air was then used as oxidant 
Table 1 Optimization of the reaction conditions ${ }^{a}$

\begin{tabular}{|c|c|c|c|c|}
\hline \multirow[b]{2}{*}{ Entry } & $\begin{array}{r}\mathrm{Ph}_{3} \mathrm{P} \\
\mathbf{1 a}\end{array}$ & $\begin{array}{c}\text { visible light } \\
\mathrm{O}_{2} \text { or air }\end{array}$ & $\begin{array}{l}P=0 \\
2 a\end{array}$ & \multirow[b]{2}{*}{$\begin{array}{l}\text { NMR yield } \\
(\%)\end{array}$} \\
\hline & Solvent & $\begin{array}{l}\text { Eosin } \\
\text { Y (mol\%) }\end{array}$ & $\begin{array}{l}\text { Time } \\
\text { (h) }\end{array}$ & \\
\hline 1 & THF & 15 & 7 & $>99$ \\
\hline 2 & $\mathrm{CCl}_{4}$ & 15 & 6 & $>99$ \\
\hline 3 & DCM & 15 & 5 & $>99$ \\
\hline 4 & Ethyl acetate & 15 & 4 & $>99$ \\
\hline 5 & $\mathrm{CH}_{3} \mathrm{CN}$ & 15 & 4 & $>99$ \\
\hline 6 & $\mathrm{MeOH}$ & 15 & 1.5 & $>99$ \\
\hline 7 & $\mathrm{DCM}: \mathrm{MeOH}=5: 1$ & 15 & 3.5 & $>99$ \\
\hline 8 & $\mathrm{DCM}: \mathrm{MeOH}=5: 1$ & 10 & 3.5 & $>99$ \\
\hline 9 & $\mathrm{DCM}: \mathrm{MeOH}=5: 1$ & 5 & 3.5 & $>99$ \\
\hline 10 & $\mathrm{DCM}: \mathrm{MeOH}=5: 1$ & 1 & 3.5 & $>99$ \\
\hline $11^{c}$ & $\mathrm{DCM}: \mathrm{MeOH}=5: 1$ & 1 & 3.5 & $>99(95)^{d}$ \\
\hline $12^{e}$ & $\mathrm{DCM}: \mathrm{MeOH}=5: 1$ & 1 & 3.5 & $91(5)^{f}$ \\
\hline $13^{g}$ & $\mathrm{DCM}: \mathrm{MeOH}=5: 1$ & 1 & 3.5 & $40(55)^{f}$ \\
\hline $14^{c}$ & $\mathrm{DCM}: \mathrm{MeOH}=5: 1$ & - & 3.5 & $30(66)^{f}$ \\
\hline $15^{c, h}$ & DCM $: \mathrm{MeOH}=5: 1$ & 1 & 10 & NR \\
\hline
\end{tabular}

${ }^{a}$ A solution of $1 \mathrm{a}(0.2 \mathrm{mmol})$ in the tested solvent $(3 \mathrm{~mL}$ in total) was irradiated by a $23 \mathrm{~W}$ household lamp at rt under $\mathrm{O}_{2}$ atmosphere $(1$ atm). ${ }^{b}$ Yield determined by ${ }^{31} \mathrm{P}$ NMR spectroscopy of the crude reaction mixture using tricyclohexylphosphin as internal standard. ${ }^{c}$ The reactions were carried out under air atmosphere (1 atm). ${ }^{d}$ Isolated yield. ${ }^{e}$ Eosin Y disodium salt was used instead of Eosin Y. ${ }^{f}$ Recovered yield of 1a. ${ }^{g}$ Fluorescein was used instead of Eosin Y. ${ }^{h}$ The reaction was carried out without light.

instead of pure oxygen, the same excellent yield was observed (entry 11, Table 1) with high quantum yield $(\Phi=0.72)$. Eosin $\mathrm{Y}$ disodium salt was then used instead of Eosin $\mathrm{Y}$ but showed slightly decreased yield (entry 12, Table 1). Non-halogenated Eosin Y derivative, fluorescein, was also tested but showed far more less reactivity (entry 13, Table 1). Finally, control experiments without Eosin Y (entry 12, Table 1) or light (entry 13, Table 1) were carried out. The results indicated that both Eosin $Y$ and light played a key role in this transformation. Thus, condition A (Eosin Y (1 mol\%), DCM : MeOH = 5:1, air (1 atm), $23 \mathrm{~W}$ household lamp, and rt) was applied for further studies.

With the optimal conditions in hand, we next examined the substrate scope of this photooxidation with a series of triarylphosphines (Table 2). Reactants with a strong electron donating group, like methoxy (2b) or ethoxy (2c), were firstly examined, which gave the desired products in excellent yields. Then some weak electron donating groups, such as methyl (2d, 2e, and $\mathbf{2 f}$ ), ethyl (2g), tert-butyl (2h), and phenyl (2i), were induced into the aryl ring of the triarylphosphines and their reactivities were tested. Good to excellent yields were generated. Electron deficient substrates with weak electron withdrawing groups ( $2 \mathbf{j}$ and $2 \mathbf{k}$ ) or strong electron withdrawing groups $(\mathbf{2} \mathbf{1}, \mathbf{2 m}$, and $\mathbf{2 n})$ were then applied under the standard conditions. The corresponding yields were quite satisfying. Notably, trinaphthylphosphine (10) and triphenylphosphine (1p) were also tolerant and showed nice reactivities in this reaction. These results demonstrated that

Table 2 Photooxidation of 1 under condition $\mathrm{A}^{a}$

\begin{tabular}{|c|c|c|}
\hline & visible light, air (1 atm) & \\
\hline $\boldsymbol{F}$ & Eosin Y (1 mol\%) & \\
\hline 1 & $\mathrm{DCM}: \mathrm{CH}_{3} \mathrm{OH}=5: 1, \mathrm{rt}$ & 2 \\
\hline
\end{tabular}

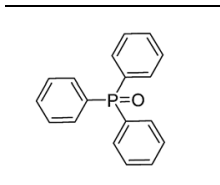

$2 a, 3.5$ h, $95 \%$

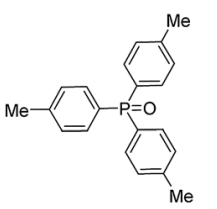

$2 d, 4 h, 89 \%$

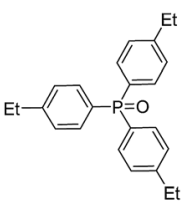

$2 \mathrm{~g}, 2.5 \mathrm{~h}, 83 \%$

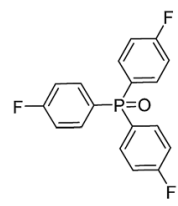

2j, $3 \mathrm{~h}, 95 \%$

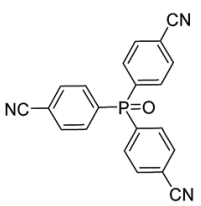

$2 \mathrm{~m}, 8 \mathrm{~h}, 94 \%$

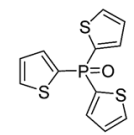

$2 p, 3.5$ h, $90 \%$

${ }^{a}$ A solution of $1(0.2 \mathrm{mmol})$, Eosin Y $(1 \mathrm{~mol} \%)$, DCM $(2.5 \mathrm{~mL})$, and $\mathrm{MeOH}(0.5 \mathrm{~mL})$ was irradiated by a $23 \mathrm{~W}$ household lamp at rt under air atmosphere $(1 \mathrm{~atm})$. Isolated yield was reported.

tolerance for a wide range of arylphosphines was achieved in this photooxidation methodology.

To gain insight to the mechanism, singlet oxygen quenching experiments were carried out using 9,10-dimethylanthracene as singlet oxygen quencher. ${ }^{2 b}$ The results were shown in Fig. 1 . The whole reaction process was inhibited by 1 equivalent of 9,10dimethylanthracene (triangle symbol). The reaction rate was even lower with the addition of 2 equivalents of 9,10-dimethylanthracene (square symbol). Since 9,10-dimethylanthracene was a typical singlet oxygen quencher, ${ }^{2 b}$ we reasoned that singlet oxygen might be the key oxidative species in the triarylphosphine 


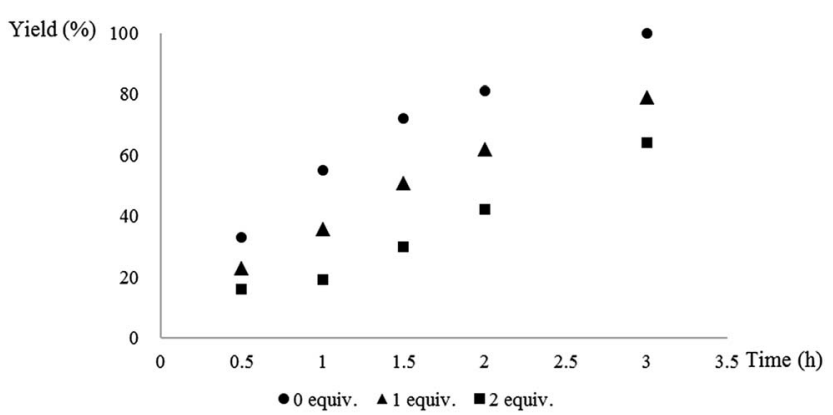

Fig. 1 Singlet oxygen quenching experiments. (Reactions were carried out under optimized conditions with 0,1 or 2 equivalents of 9,10dimethylanthracene.)

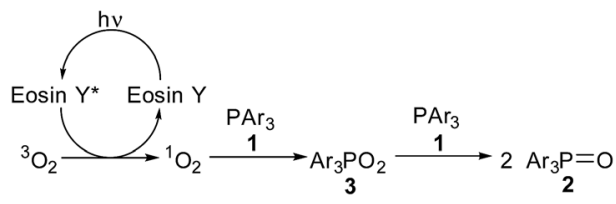

Scheme 2 Proposed mechanism.

oxidation process. The trapping product, 9,10-dimethyl-9,10dihydro-9,10-epidioxyanthracene, was also observed in crude ${ }^{1} \mathrm{H}$ NMR analysis. ${ }^{17}$ Styrene and cyclohexene was also added to the reaction system to trap phosphadioxirane, but no trapping species was detected. ${ }^{\mathbf{1 8 a}}$

On the basis of the above results and literature precedence, ${ }^{18}$ a possible mechanism was proposed in Scheme 2. Upon the irradiation of visible light, Eosin Y reaches its excited state. ${ }^{2 c}$ Then energy transfer between Eosin $\mathrm{Y}^{*}$ and oxygen $\left({ }^{3} \mathrm{O}_{2}\right)$ gave singlet oxygen $\left({ }^{1} \mathrm{O}_{2}\right)$, and Eosin $\mathrm{Y}$ went back to ground state. ${ }^{2 a}$ Triarylphosphine 1 and singlet oxygen $\left({ }^{1} \mathrm{O}_{2}\right)$ combined to afford triarylphosphadioxane $3 .^{18 a} 3$ and another molecule of 1 finally furnished 2 as the product. ${ }^{18 b}$

\section{Conclusions}

In conclusion, a visible light-induced metal-free photo oxidation of triarylphosphines was developed. Eosin Y was employed as the catalyst and air was used as the oxidant. Considering that this protocol is cheap, environmental friendly, easy to operate, and the substrate scope is broad, this method may be widely used in the oxidation of phosphine derivatives.

\section{Acknowledgements}

We greatly acknowledge the financial support from International Science \& Technology Cooperation Program of China (2014DFE40130).

\section{Notes and references}

1 (a) D. P. Hari and B. König, Angew. Chem., Int. Ed., 2013, 52, 4734-4743; (b) R. Brimioulle, D. Lenhart, M. M. Maturi and
T. Bach, Angew. Chem., Int. Ed., 2015, 54, 3872-3890; (c) S. Poplata, A. Tröster, Y. Zou and T. Bach, Chem. Rev., 2016, 116, 9748-9815.

2 (a) M. C. Derosa and R. J. Crutchley, Coord. Chem. Rev., 2002, 233/234, 351-371; (b) A. A. Gorman and M. A. J. Rodgers, Chem. Soc. Rev., 1981, 10, 205; (c) F. Amat-Guerri, M. M. C. López-González, R. Martínez-Utrilla and R. Sastre, J. Photochem. Photobiol., A, 1990, 53, 199-210.

3 D. R. Kearns, Chem. Rev., 1971, 71, 395-427.

4 F. Xue, M. Shi, Y. Yan, H. Yang, Z. Zhou and S. Yang, RSC Adv., 2016, 6, 15509-15512.

5 P. R. Ogilby, Chem. Soc. Rev., 2010, 39, 3181.

6 (a) A. Pace and E. L. Clennan, J. Am. Chem. Soc., 2002, 124, 11236-11237; (b) D. Kalaitzakis, T. Montagnon, I. Alexopoulou and G. Vassilikogiannakis, Angew. Chem., Int. Ed., 2012, 51, 8868-8871; (c) R. Gao, D. G. Ho, B. Hernandez, M. Selke, D. Murphy, P. I. Djurovich and M. E. Thompson, J. Am. Chem. Soc., 2002, 124, 1482814829; (d) D. B. Ushakov, K. Gilmore, D. Kopetzki, D. T. McQuade and P. H. Seeberger, Angew. Chem., Int. Ed., 2014, 53, 557-561; (e) T. Taniguchi, D. Hirose and H. Ishibashi, ACS Catal., 2011, 1, 1469-1474.

7 (a) B. M. Estevão, D. S. Pellosi, C. F. de Freitas, D. Vanzin, D. S. Franciscato, W. Caetano and N. Hioka, J. Photochem. Photobiol., A, 2014, 287, 30-39; (b) L. S. Herculano, L. C. Malacarne, V. S. Zanuto, G. V. B. Lukasievicz, O. A. Capeloto and N. G. C. Astrath, J. Phys. Chem. B, 2013, 117, 1932-1937; (c) Y. C. Teo, Y. Pan and C. H. Tan, ChemCatChem, 2013, 5, 235-240; (d) Z. Barbieriková, M. Mihalíková and V. Brezová, Photochem. Photobiol., 2012, 88, 1442-1454; (e) D. S. Pellosi, B. M. Estevão, J. Semensato, D. Severino, M. S. Baptista, M. J. Politi, N. Hioka and W. Caetano, J. Photochem. Photobiol., A, 2012, 247, 8-15; $(f)$ M. Scholz, R. Dědic, T. Breitenbach and J. Hála, Photochem. Photobiol. Sci., 2013, 12, 1873-1884.

8 Y. Gao, G. Lu, P. Zhang, L. Zhang, G. Tang and Y. Zhao, Org. Lett., 2016, 18, 1242-1245.

9 J. Li, D. Ding, Y. Tao, Y. Wei, R. Chen, L. Xie, W. Huang and H. Xu, Adv. Mater., 2016, 28, 3122-3130.

10 (a) T. Yu, Y. Wang, X. Hu and P. Xu, Chem. Commun., 2014, 50, 7817-7820; (b) X. Zeng, Z. Cao, X. Wang, L. Chen, F. Zhou, F. Zhu, C. Wang and J. Zhou, J. Am. Chem. Soc., 2016, 138, 416-425; (c) C. J. A. Warner, A. T. Reeder and S. Jones, Tetrahedron: Asymmetry, 2016, 27, 136-141; (d) H. M. Al-Saidi, J. Saudi Chem. Soc., 2016, 20, 615-624.

11 (a) L. Wang, Y. Wang, M. Chen and M. Ding, Adv. Synth. Catal., 2014, 356, 1098-1104; (b) M. Schirmer, S. Adomeit, A. Spannenberg and T. Werner, Chem.-Eur. J., 2016, 22, 2458-2465.

12 H. Pan, H. Huang, W. Liu, H. Tian and Y. Shi, Org. Lett., 2016, 18, 896-899.

13 N. Oka, R. Kajino, K. Takeuchi, H. Nagakawa and K. Ando, J. Org. Chem., 2014, 79, 7656-7664.

14 (a) K. A. Prokop and D. P. Goldberg, J. Am. Chem. Soc., 2012, 134, 8014-8017; (b) E. K. Beloglazkina, A. G. Majouga, A. A. Moiseeva, N. V. Zyk and N. S. Zefirov, Mendeleev 
Commun., 2009, 19, 69-71; (c) K. E. Elson, I. D. Jenkins and W. A. Loughlin, Tetrahedron Lett., 2004, 45, 2491-2493.

15 (a) K. Ohkubo, T. Nanjo and S. Fukuzumi, Bull. Chem. Soc. Jpn., 2006, 79, 1489-1500; (b) S. Yasui, S. Tojo and T. Majima, J. Org. Chem., 2005, 70, 1276-1280; (c) K. Ohkubo, H. Kotani and S. Fukuzumi, Chem. Commun., 2005, 4520-4522; (d) R. Gao, D. G. Ho, T. Dong, D. Khuu, N. Franco, O. Sezer and M. Selke, Org. Lett., 2001, 3, 37193722 .

16 A. Ding, Y. Wang, R. Rios, J. Sun, H. Li and H. Guo, J. Saudi Chem. Soc., 2015, 19, 706-709.
17 (a) J. M. Carney, R. J. Hammer, M. Hulce, C. M. Lomas and D. Miyashiro, Tetrahedron Lett., 2011, 52, 352-355; (b) J. M. Carney, R. J. Hammer, M. Hulce, C. M. Lomas and D. Miyashiro, Synthesis, 2012, 44, 2560-2566.

18 (a) D. G. Ho, R. Gao, J. Celaje, H. Y. Chung and M. Selke, Science, 2003, 302, 259-262; (b) S. Tsuji, M. Kondo, K. Ishiguro and Y. Sawaki, J. Org. Chem., 1993, 58, 50555059; (c) C. P. Mane, S. V. Mahamuni, A. P. Gaikwad, R. V. Shejwal, S. S. Kolekar and M. A. Anuse, J. Saudi Chem. Soc., 2015, 19, 46-53; (d) B. Stewart, A. Harriman and L. J. Higham, Organometallics, 2011, 30, 5338-5343. 